\title{
CDKN2A NM_000077.4:C.439G>A
}

National Cancer Institute

\section{Source}

National Cancer Institute. CDKN2A NM 000077.4:C.439G>A. NCI Thesaurus. Code C146947.

A nucleotide substitution at position 439 of the coding sequence of the CDKN2A gene where guanine has been mutated to adenine. 